\title{
Studies of Peptide a- and b-Type Fragment Ions Using Stable Isotope Labeling and Integrated Ion Mobility/Tandem Mass Spectrometry
}

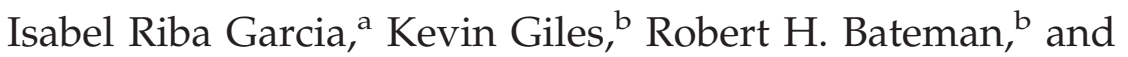 \\ Simon J. Gaskell ${ }^{\mathrm{a}}$ \\ ${ }^{a}$ Michael Barber Centre for Mass Spectrometry, School of Chemistry and Manchester Interdisciplinary \\ Biocentre, University of Manchester, Manchester, United Kingdom \\ ${ }^{\mathrm{b}}$ Waters MS Technologies Centre, Manchester, United Kingdom
}

The structures of peptide a- and b-type fragment ions were studied using synthetic peptides including a set of isomeric peptides, differing in the sequence location of an alanine residue labeled with ${ }^{15} \mathrm{~N}$ and uniformly with ${ }^{13} \mathrm{C}$. The pattern of isotope labeling of second-generation fragment ions derived via $\mathrm{a}_{n}$ and $\mathrm{b}_{n}$ ions (where $n=4$ or 5 ) suggested that these intermediates existed in part as macrocyclic structures, where alternative sites of ring opening gave rise to different linear forms whose simple cleavage might give rise to the observed final products. Similar conclusions were derived from combined ion mobility/tandem MS analyses where different fragmentation patterns were observed for isomeric a- or b-type ions that display different ion mobilities. These analyses were facilitated by a new approach to the processing of ion mobility/tandem MS data, from which distinct and separate product ion spectra are derived from ions that are incompletely separated by ion mobility. Finally, an example is provided of evidence for a macrocyclic structure for $b_{n}$ ions where $n=8$ or 9. (J Am Soc Mass Spectrom 2008, 19, 1781-1787) @ 2008 Published by Elsevier Inc. on behalf of American Society for Mass Spectrometry

$\mathrm{T}$ The field of proteomics relies heavily on tandem mass spectrometric (MS/MS) analysis of proteolytic peptides to yield full or partial sequence identification, enabling the recognition of the precursor proteins. Although the major features of peptide ion fragmentation are well understood, a more detailed understanding may have significance for improved peptide identification, including the analysis of mixtures.

We and others have previously demonstrated that current understanding of peptide fragmentation mechanisms does not readily explain all the fragment ions observed in the product ion spectra obtained from collision-induced dissociation (CID) of protonated peptides [1, 2].

The b-ions have been considered to consist most commonly of a linear peptide chain terminating in a cyclic oxazolone structure [3]; subsequent formation of a-ions by loss of $\mathrm{CO}$ has been presumed to follow the opening of the oxazolone ring. Yagüe et al. [4] proposed rearrangement of b-ions to give macrocyclic intermediate structures that could fragment further to yield products in more complete agreement with observed data. More recently, Har-

Address reprint requests to Professor Simon J. Gaskell, University of Manchester, Michael Barber Centre for Mass Spectrometry, School of Chemistry and Manchester Interdisciplinary Biocentre, John Garside Building, 131 Princess Street, Manchester M1 7DN, United Kingdom. E-mail: simon.gaskell@manchester.ac.uk rison et al. [1] provided strong evidence for a cyclic structure for the $b_{5}$-ion moiety for YAGFL- $\mathrm{NH}_{2}$. Current ideas $[2,4-8]$ also suggest a mixture of possible linear and cyclic structures for a-ions.

Using ion mobility separation in concert with MS/MS, we have provided further evidence for such a macrocyclic $\mathrm{b}$-ion in free $\mathrm{N}$-terminal peptides, with second-generation fragmentation giving "nondirect sequence" secondgeneration product ions [2]. The $b_{5}$ fragment ion obtained from YAGFL- $\mathrm{NH}_{2}$ appeared to be present as a single structure, but at least two structures were observed corresponding to the $\mathrm{a}_{4}$-ion. The higher-mobility species (i.e., smaller interaction cross section) was attributed to a macrocyclic form and was shown to yield second-generation fragment ions consistent only with such a structure.

Others have reported "nondirect sequence" fragment ions from larger peptides [6], including sequences in which the presence of a proline residue might be considered to disfavor a macrocyclic structure. A large study was performed by Mouls et al. [9], where several parameters were evaluated including peptide length, molecular weight and degrees of freedom, amino acid composition with particular attention to the $\mathrm{N}$ - and C-terminal residues, and the charge state of the precursor ion. Nondirect sequence fragment ions were observed in all cases, with no obvious dependence on the parameters studied.
(C) 2008 Published by Elsevier Inc. on behalf of American Society for Mass Spectrometry. 1044-0305/08/\$32.00

doi:10.1016/j.jasms.2008.09.024
Published online September 30, 2008 Received June 17, 2008 Revised September 15, 2008 Accepted September 22, 2008 
Here we report new findings relating to the structures of peptide a- and b-ions, obtained using ion mobility mass spectrometry and stable isotope labeling. Stable isotope labeling, using both ${ }^{15} \mathrm{~N}$ and ${ }^{13} \mathrm{C}$, enables conclusions concerning the loss of small fragments, whereas ion mobility separations, particularly in conjunction with both prior and subsequent ion fragmentation, provide evidence for the homogeneity, or otherwise, of ion populations.

\section{Experimental}

Materials

Labeled peptides (A*YGFL-OH, YA*GFL-OH, YGA*FL$\left.\mathrm{OH}, \mathrm{YGFA}{ }^{*} \mathrm{~F}-\mathrm{OH}, \mathrm{YGFLA}^{*}-\mathrm{OH}\right)$ were obtained from $\mathrm{CK}$ Gas Products Ltd. (Hook, Hampshire, UK). (Throughout, peptide sequences are shown with the suffixes $-\mathrm{OH}$ or $-\mathrm{NH}_{2}$, to indicate C-terminal carboxylic acid or amide

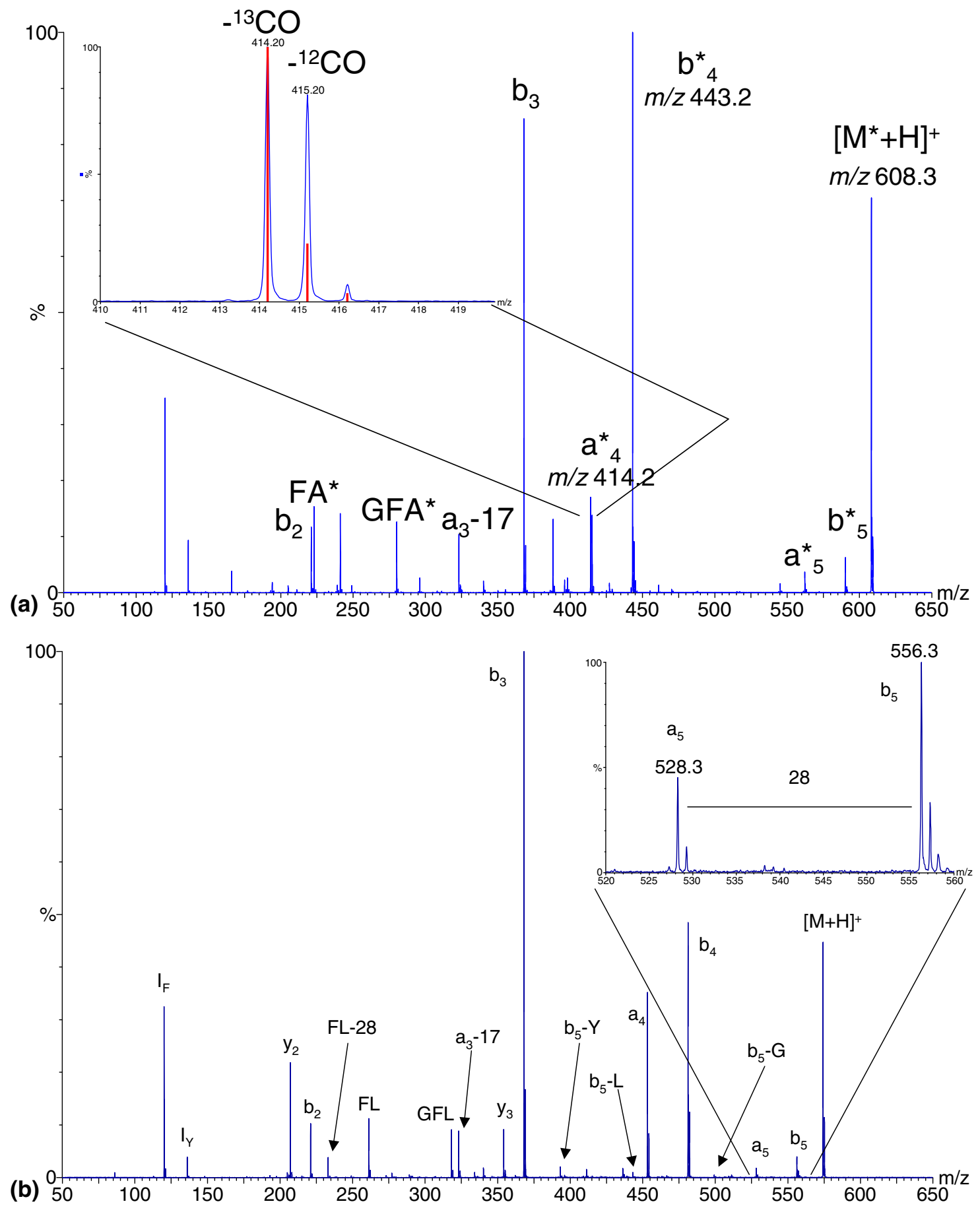

Figure 1. (a) Product ion spectrum of singly protonated $\mathrm{YGFA} * \mathrm{~F}-\mathrm{OH}$ at $m / z$ 608.3. The insert indicates the isotopic variants of the $\mathrm{a}_{4}$ ion, with vertical lines indicating the expected relative abundances of the ${ }^{13} \mathrm{C}$ variants if the $\mathrm{a}_{4}$ ion arose via loss of ${ }^{13} \mathrm{CO}$ from the alanine residue. (b) Product ion spectrum of singly protonated YGFLA ${ }^{*}-\mathrm{OH}$ at $m / z 574.3$. The insert indicates the difference of 28 Th between the $b_{5}$ and the $a_{5}$ ion. 
groups, respectively.) In all cases, the Ala residue $\left(\mathrm{A}^{*}\right)$ was ${ }^{15} \mathrm{~N}$-labeled and ${ }^{13} \mathrm{C}$-labeled at all positions. Other peptides [angiotensin I (DRVYIHPFHL-OH), human $\beta$-casomorphin (YPFVEPI-OH), and neurokinin (DMHDFFVGLM-NH $\mathrm{N}_{2}$ )], formic acid, acetonitrile, and water were obtained from Sigma (Poole, UK).

\section{Mass Spectrometry and Ion Mobility Spectrometry}

For MS/MS (without concomitant ion mobility analyses), samples were diluted to a concentration of 1 $\mathrm{pmol} / \mu \mathrm{L}$ using acetonitrile/water $(1 / 1, \mathrm{vol} / \mathrm{vol})$ containing $0.1 \%$ formic acid, and infused using gold-coated glass capillaries (Proxeon, Odense, Denmark) into the electrospray ionization (ESI) source of a Micromass Q-ToF I instrument upgraded to Q-ToF II specifications (Waters, Manchester, UK). The capillary voltage, cone voltage, and source temperature were approximately $1.4 \mathrm{kV}, 45 \mathrm{~V}$, and $60^{\circ} \mathrm{C}$, respectively. Mass spectra were acquired every $2.4 \mathrm{~s}$. The instrument was calibrated using the product ions obtained from fragmentation of doubly protonated Glu-fibrinopeptide B from $\mathrm{m} / \mathrm{z} 50$ to 1500. Instrument control and data acquisition were performed using MassLynx V3.4 software (Waters).

For mobility experiments, samples were diluted to a concentration of $0.5 \mathrm{pmol} / \mu \mathrm{L}$ using acetonitrile/water $(1 / 1, \mathrm{vol} / \mathrm{vol})$ containing $0.1 \%$ formic acid and infused at a flow rate of $3 \mu \mathrm{L} / \mathrm{min}$ into the ESI source of a Synapt HDMS instrument (Waters) for ion mobility and mass spectrometric analysis. The Synapt instrument has a hybrid quadrupole/ion mobility/orthogonal acceleration time-of-flight (oa-ToF) geometry; a full description of this instrument has been presented previously [10]. In brief, the ion mobility separation stage of the Synapt consists of three ion guides. The first (Trap) is used to accumulate ions before mobility separation, the second (IM) performs the ion mobility separation, and the third (Transfer) transfers the mobility-separated ions to the oa-ToF analyzer. Ion mobility separation is achieved using a repeating sequence of traveling voltage waves (T-Waves) to propel ions through an atmosphere of nitrogen. Ion mobility spectra are recorded by synchronizing the oa-Tof mass spectra acquisitions with the gated release of ions from the Trap ion guide into the IM separation guide. For the experiments reported here, ions were released over a $100-\mu$ s period into the IM guide and 200 sequential mass spectra (representing 13-ms total acquisition time) of the mobility-separated ions were recorded to yield arrival time distributions (ATDs). The IM guide was operated at a pressure of 0.5 mbar of nitrogen and the Trap and Transfer guides were operated at a pressure of approximately 0.03 mbar ( 1/1, vol/vol, nitrogen/argon). The IM guide T-Wave was operated at $300 \mathrm{~m} / \mathrm{s}$ and linearly ramped in amplitude from 5 to $20 \mathrm{~V}$ over each 13-ms experiment. The Transfer guide T-Wave was operated at $247 \mathrm{~m} / \mathrm{s}$ with a constant 3-V amplitude.

For IM acquisitions with no fragmentation, ion injection voltages into the Trap and Transfer regions were set at 5 and $3 \mathrm{~V}$, respectively. Ion fragmentation pre- or post-IM separation was achieved by increasing the Trap or Transfer ion injection voltages, respectively. Instrument control and data acquisition were performed using MassLynx V4.1 software (Waters).

\section{Results and Discussion}

The singly protonated ion from labeled YGFA*F-OH at $m / z 608.3$ was selected for CID in the Q-ToF I. The resulting product ion spectrum (Figure 1a) includes isotopic variants of the $\mathrm{a}_{4}$ ion that correspond to differences of both ${ }^{13} \mathrm{CO}(29 \mathrm{Th})$ and ${ }^{12} \mathrm{CO}(28 \mathrm{Th})$ from the $\mathrm{b}_{4}$ ion. One explanation consistent with these observations is that the $\mathrm{a}_{4}$ ion is formed, at least in part, by fragmentation of a
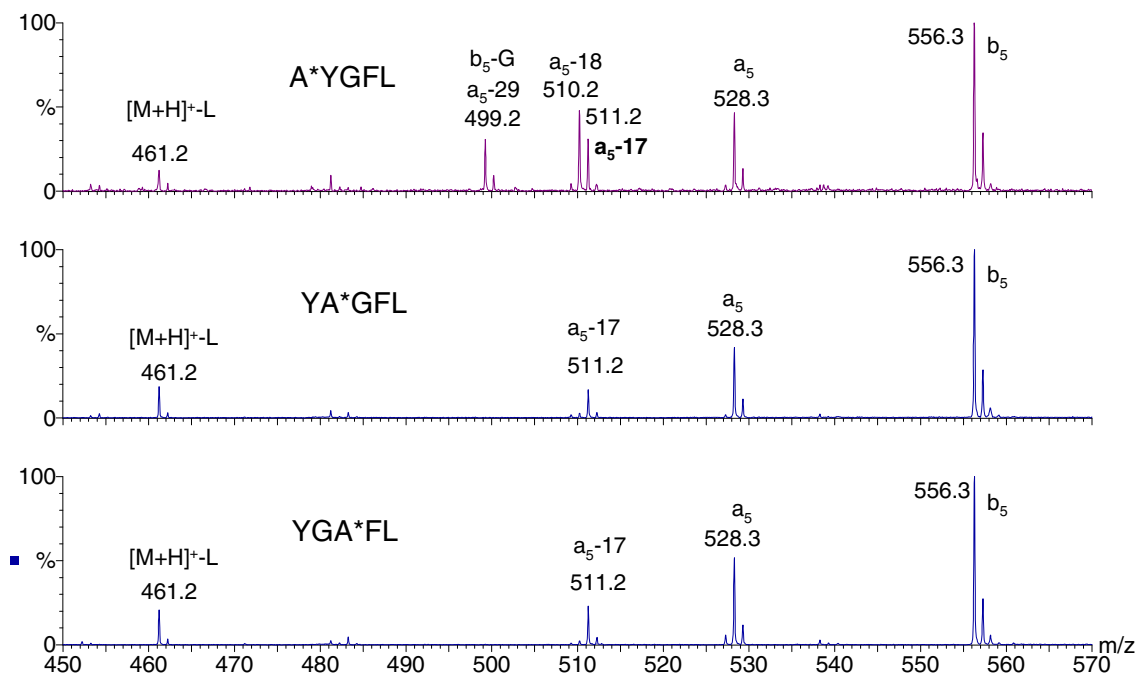

Figure 2. Partial product ion spectra of $m / z 574.3$ from singly protonated A*YGFL-OH, YA*GFL-OH, and YGA*FL-OH showing the loss of ammonia from $a_{5}$ ions. Significant loss of ${ }^{14} \mathrm{NH}_{3}$ from the $\mathrm{a}_{5}$ ion of $\mathrm{A}^{*} \mathrm{YGFL}-\mathrm{OH}$ is consistent with the intermediacy of a cyclic structure. 
b-ion population $\left(b_{4}\right.$ or $\left.b_{5}\right)$ with a linear structure where the amino acid sequence is reordered by the intermediacy of a macrocyclic structure. The fragmentation of $b_{4}$ was also investigated and the results showed the same heterogeneity regarding the $a_{4}$ ions as observed from fragmentation of the precursor $[\mathrm{M}+\mathrm{H}]^{+}$ion (data not shown). The combination of ion mobility separation and MS/MS provides further evidence for this hypothesis, as discussed in the following text.

Figure $1 \mathrm{~b}$ shows the product ion spectrum derived by CID (Q-ToF I instrument) of the singly protonated ion from the labeled peptide YGFLA*-OH at $m / z$ 574.3. The $b_{5}$ ion (here representing loss of $\mathrm{H}_{2} \mathrm{O}$ ) is observed at the expected $m / z$ value of 556.3. [Isomeric [M $+\mathrm{H}-$ $\left.\mathrm{H}_{2} \mathrm{O}\right]^{+}$structures may also be represented, corresponding to water loss from a location other than the C- terminus [11]; this does not diminish the significance of the observations concerning the formation of secondgeneration fragments with a reordered amino acid sequence (Figure 1b).] The $a_{5}$ ion is also isotopically homogeneous but appears at $m / z$ 528.3, representing loss of $\left[{ }^{12} \mathrm{CO}, \mathrm{H}_{2} \mathrm{O}\right]$, rather than the expected $\left[{ }^{13} \mathrm{CO}\right.$, $\mathrm{H}_{2} \mathrm{O}$ ], from the protonated peptide. This might be explained by the intermediacy of a cyclic $b_{5}$ ion where ring opening at several possible sites results in loss of ${ }^{12} \mathrm{CO}$. If this is the case, however, the almost complete lack of evidence for loss of ${ }^{13} \mathrm{CO}$ suggests that ring opening at the original site of macrocycle formation is specifically disfavored in this instance. Further investigations are required into the structures of the $a_{4} / a_{5}$ ions, including molecular modeling and additional selective labeling studies.

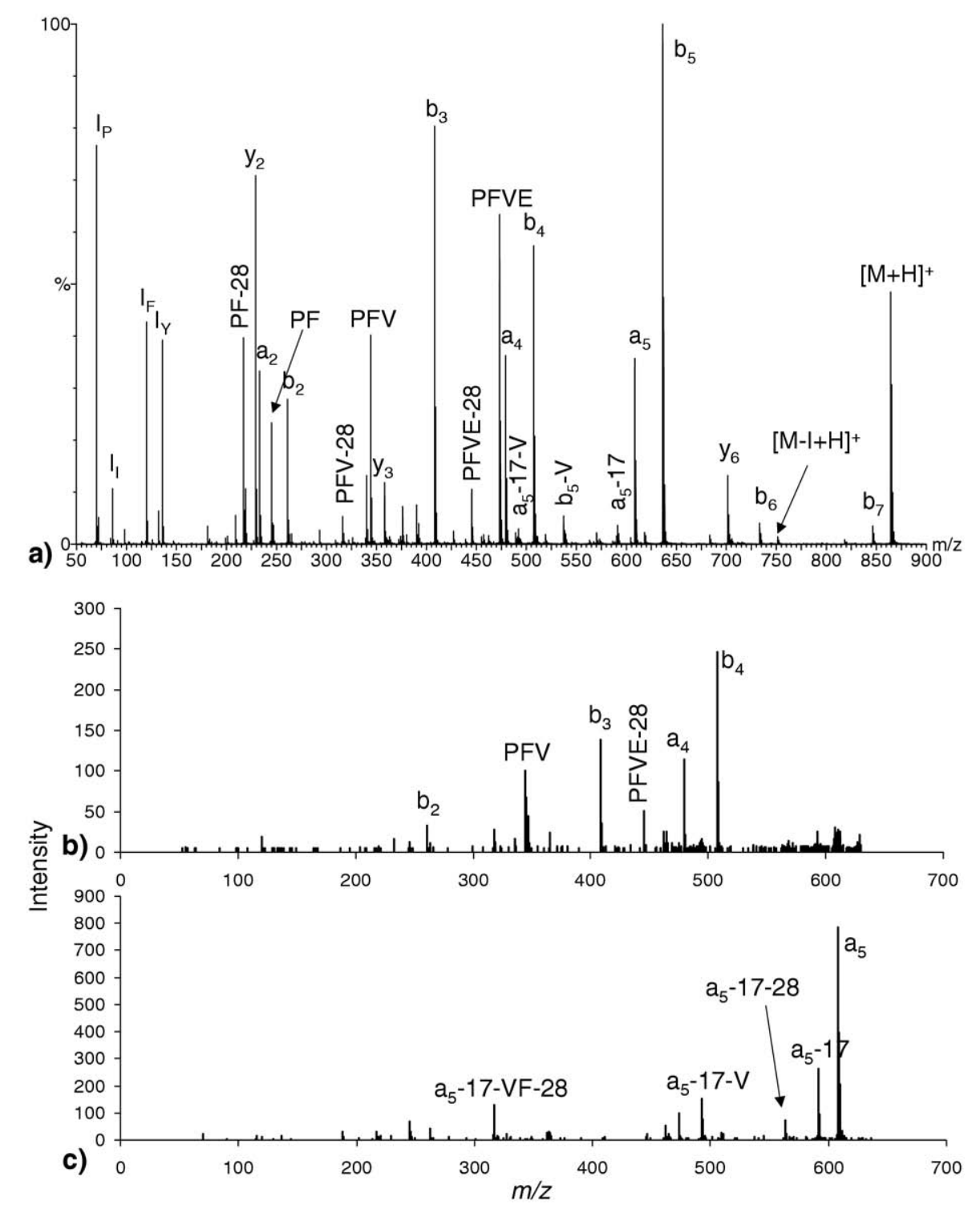

Figure 3. (a) Product ion spectrum of singly protonated casomorphin (YPFVEPI-OH) at $\mathrm{m} / \mathrm{z} 864.5$. Second-generation product ion spectra derived from $a_{5}$ ions corresponding to the leading (b) and trailing (c) edges of the ATD from mobility separation of $a_{5}$ ions produced in the ion source from protonated casomorphin (YPFVEPI-OH). 
In our previous studies using combined ion mobilityMS/MS [2] we showed that the $\mathrm{a}_{4}$ ion from protonated YAGFL-NH $\mathrm{N}_{2}$ is a mixture of structures, consistent with the suggestion of Polfer et al. [7] of N-terminal cyclization of a-ions. In the present study, CID was performed on singly protonated ions from a set of isomeric labeled peptides (A*YGFL-OH, YA*GFL-OH, and YGA*FL-OH) where the $\left[{ }^{13} \mathrm{C},{ }^{15} \mathrm{~N}\right]$ alanine residue is positioned at different distances from the N-terminus. Figure 2 shows a comparison of the high $\mathrm{m} / \mathrm{z}$ region of the product ion spectra from these peptides (full spectra are included in the supplementary material, which can be found in the electronic version of this article) where the loss of $\mathrm{NH}_{3}$ from the $a_{5}$ fragment ion is observed, presumably from the N-terminus, as suggested by Vachet et al. [12] and studied in detail by Cooper et al. [13]. The $\left(\mathrm{a}_{5}-17\right)$ ion at $\mathrm{m} / \mathrm{z}$ 511.3, representing loss of ${ }^{14} \mathrm{NH}_{3}$, is observed as expected for $\mathrm{YA}^{*} \mathrm{GFL}-\mathrm{OH}$ and $\mathrm{YGA}^{*} \mathrm{FL}-\mathrm{OH}$. In the case of $A^{*} Y G F L-O H$, the ion at $m / z 510.3$ represents loss of ${ }^{15} \mathrm{NH}_{3}$ from the $\mathrm{N}$-terminal amino acid. The relative abundance of $m / z 511.3$, however, indicates a significant contribution arising from loss of ${ }^{14} \mathrm{NH}_{3}$. This observation is consistent with a macrocyclic component of the $a_{5}$ ion population, with ring opening at alternative positions before loss of ammonia.

Paizs and coworkers [14] concluded that an $a_{2}-17$ was observed only in tripeptides containing Gly at position 2 and not when position 2 was occupied by Ala or Pro. Here we observed a-17 fragment ions in peptides containing either Gly or other amino acids at the cleavage position. Also, the observation of the loss of ${ }^{14} \mathrm{NH}_{3}$, rather than ${ }^{15} \mathrm{NH}_{3}$, from a-ions from YA*GFL-OH (Figure 2) contrasts with the observations by Bythell et al. [14] of the loss of ${ }^{15} \mathrm{NH}_{3}$ from labeled Gly at position 2 in tripeptides, but not at position 1 . This may suggest mechanistic complexities in longer peptides beyond those suggested by Bythell et al. [14], perhaps associated with the intermediacy of a macrocyclic structure and subsequent selectivity of ring cleavage.

We have previously shown [2] the presence of at least two structures for the $\mathrm{a}_{4}$ ion from YAGFL- $\mathrm{NH}_{2}$, one corresponding to a more compact, possibly macrocyclic, structure. The extent to which macrocycle formation is dependent on both chain length and amino acid composition is yet to be fully understood.

The peptide casomorphin (YPFVEPI-OH) was then studied, exploiting the highly favored fragmentation of the singly protonated precursor $(m / z ~ 864.5)$ to yield a prominent $a_{5}$ ion $(m / z$ 608.3; Figure $3 a)$, as expected from cleavage adjacent to the proline residue. The product ion spectrum also shows the presence of b- and a-ions that cannot be produced by direct cleavage of the peptide chain, and therefore apparently reflect the formation of a macrocyclic intermediate. Protonated casomorphin was then fragmented in the ESI source by increasing the cone voltage. The resulting $\mathbf{a}_{5}$ ion at $\mathrm{m} / z$ 608.3 was selected in the resolving quadrupole and separated by ion mobility; as the different structures emerged from the ion mobility region they were sub- jected to fragmentation by increasing the ion injection voltages in the transfer guide. In this instance the mobility data were processed using in-house software (Waters), which allows the generation of distinct product ion spectra from ion populations incompletely separated on the basis of mobility. Thus, only product ions whose abundances maximize within the same defined precursor arrival time window are accumulated into the same product ion spectrum. Two distinct $a_{5}$ ion populations were differentiated in this manner: the spectrum associated with the precursor of higher mobility is shown in Figure $3 b$ and that derived from the precursor of lower mobility is shown in Figure 3c. The differences between the spectra are clear. The higher-mobility variant fragments in a manner consistent with a linear structure, yielding ions attributable to simple cleavage of the non-rearranged sequence. Interestingly, the fragmentations of the lower-mobility variant of the $a_{5}$ ion cannot be explained without rearrangement.

The same data processing approach was adopted following equivalent analysis of protonated angiotensin I (DRVYIHPFHL-OH; data not shown). Ion mobility separation and subsequent fragmentation of the $\mathrm{a}_{4}$ ion $(\mathrm{m} / \mathrm{z} 506.3)$ again provided evidence of at least two structures.

As a final component of the present study, the potential for macrocycle formation in larger fragment ions was examined. The peptide neurokinin, DMHDFFVGLM-NH $\mathrm{N}_{2}$, was analyzed using the Synapt HDMS instrument to enable concomitant MS/MS and ion mobility analyses. The product ion spectrum of the doubly protonated peptide at $m / z 608.5$ (Figure 4) indicated the presence of fragment ions whose origin is attributable to the ring opening of intermediate macrocyclic structures. Prominent examples included ions of $m / z$ 963.4, attributed to $\left[\mathrm{b}_{9}-\mathrm{V}\right]$, and $m / z$ 850.2, attributed to $\left[\mathrm{b}_{8}-\mathrm{V}\right]$. Cone voltage fragmentation in the ESI source produced $b_{9}$ and $b_{8}$ as major product ions. The product ion spectrum derived from further fragmentation of $b_{9}$ ions (not shown) included fragments $\left(\left[b_{9}-V\right],\left[b_{9}-F\right]\right)$ whose origin was consistent with a macrocyclic structure for the $b_{9}$ ion. When the $b_{9}$ ion was separated according to mobility

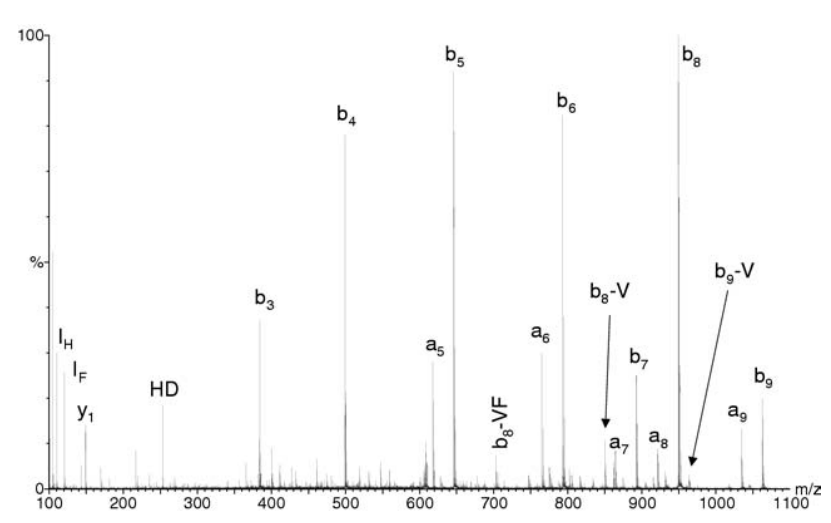

Figure 4. Spectrum of product ions derived from neurokinin $\left(\right.$ DMHDFFVGLM-NH $\left.H_{2}\right)[\mathrm{M}+2 \mathrm{H}]^{2+}$ at $\mathrm{m} / \mathrm{z} 605.8$. 
and fragmentation was subsequently performed, however, no separation into discrete structures was observed. The arrival time distributions (ATDs) for the $b_{9}$ ion and for the second-generation fragment ions were of similar shape and width to that of a single component of similar mobility (data not shown). We cannot now unambiguously differentiate between the two possible conclusions: first, that the $b_{9}$ ion population is structurally homogeneous and, second, that the mobility separation has insufficient resolution to separate discrete forms.

When the $b_{8}$ ion at $m / z 949.3$ derived from neurokinin was selected for CID (without mobility separation), the product ion spectrum showed the presence of rearranged or scrambled fragment ions (Figure 5a). When the $b_{8}$ ion was formed in the ion source and separated according to mobility, a shoulder was clearly observed on the ATD (Figure 5b). Fragmentation of $b_{8}$ was then promoted by increasing the ion injection voltage at the transfer guide; the spectra thus obtained from the leading and trailing edges of the ATD [using the in-house deconvolution software (Waters)] show clear differences in ion abundance and type (Figure 5c). This observation indicates the presence of at least two stable structures for the $b_{8}$ ion, which is consistent with previous observations by Clemmer and coworkers [15] who used ion mobility to demonstrate two structures for several b-ions from bradykinin. (a)

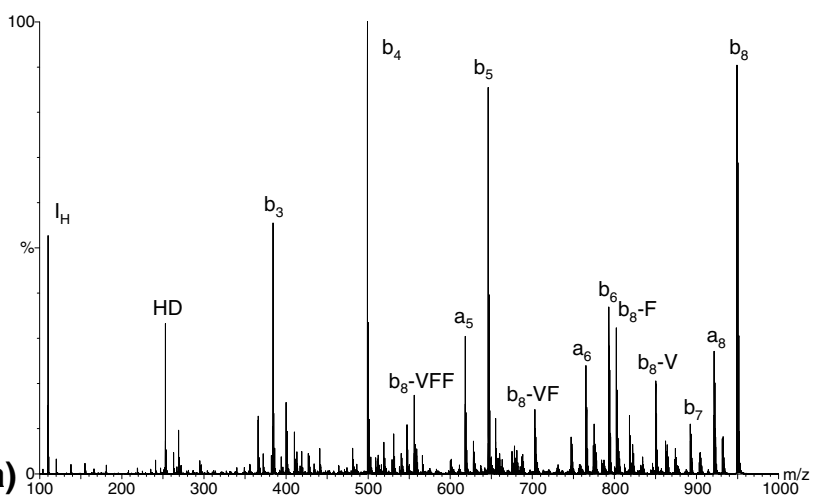

(b)

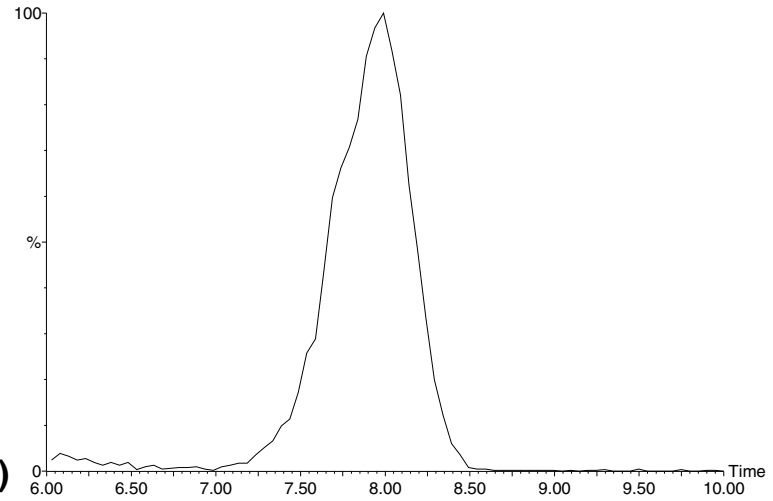

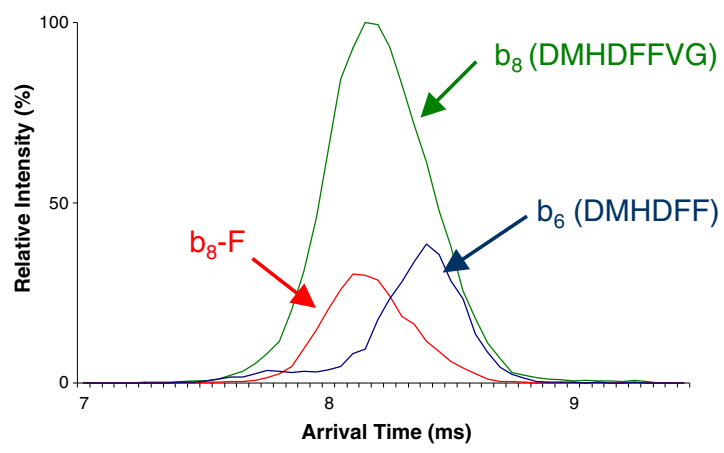
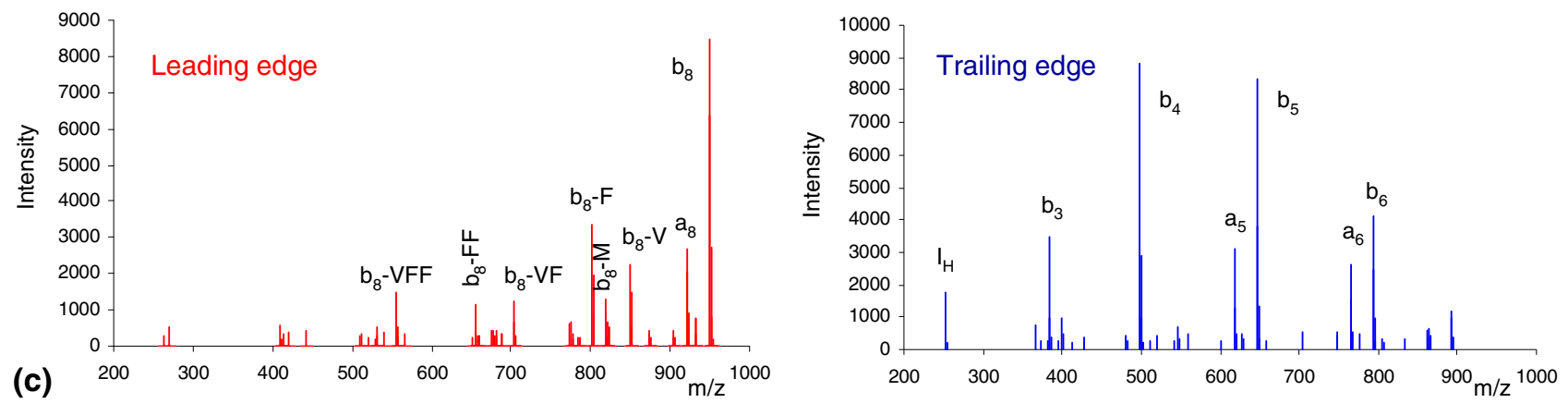

Figure 5. (a) Second-generation product ion spectrum derived from $\mathrm{m} / \mathrm{z} 949.4$, corresponding to the $\mathrm{b}_{8}$ fragment ion from neurokinin (DMHDFFVGLM-NH $\mathrm{N}_{2}$ ). (b) Arrival time distribution corresponding to the $b_{8}$ ion from neurokinin (DMHDFFVGLM-NH$)_{2}$ ), formed in the source and analyzed according to mobility. (c) Arrival time distributions corresponding to precursor ion $b_{8}$, second-generation fragment ions $b_{8}-F$ and $b_{6}$ obtained from $b_{8}$. Second-generation product ion spectra derived from $b_{8}$ ions corresponding to the leading and trailing edges of the ATD from mobility separation of $b_{8}$ ions produced in the ion source from protonated neurokinin (DMHDFFVGLM- $\mathrm{NH}_{2}$ ). 


\section{Conclusions}

We have demonstrated using ion mobility in conjunction with MS/MS that different second-generation fragment ions are observed for isomeric a- or b-ions that display different ion mobilities. A new approach to the processing of ion mobility-MS/MS data has been demonstrated, enabling discrete product ion spectra to be obtained from ions that are incompletely separated by ion mobility. Furthermore, isotope labeling studies (using both ${ }^{15} \mathrm{~N}$ and ${ }^{13} \mathrm{C}$ ) have substantiated the conclusion that intermediates in the formation of a number of peptide fragment ions are macrocyclic in form; their subsequent cleavage (which may be highly selective) yields products in which the sequence of amino acids is changed. Evidence derived from the study of $b_{n}$ ions, where $n$ is as large as 9 , also suggests a contribution of macrocyclic structures. The evident complexity of the fragmentation processes associated with the tandem mass spectrometric analysis of peptides suggests that continuing study is required to enable the most productive use of such data in the characterization of peptides and proteins.

\section{Acknowledgments}

We thank the UK Biotechnology and Biological Sciences Research Council for financial support (Grants EP/D013615/1 and IIP0307/ 005).

\section{References}

1. Harrison, A. G.; Young, A. B.; Bleiholder, C.; Suhai, S.; Paizs, B. Scrambling of Sequence Information in Collision-Induced Dissociation of Peptides. J. Am. Chem. Soc. 2006, 128, 10364-10365.
2. Riba-Garcia, I.; Giles, K.; Bateman, R. H.; Gaskell, S. J. Evidence for Structural Variants of a- and b-Type Peptide Fragment Ions Using Combined Ion Mobility/Mass Spectrometry. J. Am. Soc. Mass Spectrom. 2008, 19, 609-613.

3. Yalcin, T.; Khouw, C.; Csizmadia, I. G.; Peterson, M. R.; Harrison, A. G. Why Are b Ions Stable Species in Peptide Spectra? J. Am. Soc. Mass Spectrom. 1995, 6, 1165-1174.

4. Yague, J.; Paradela, A.; Ramos, M.; Ogueta, S.; Marina, A.; Barahona, F.; Lopez de Castro, J. A.; Vazquez, J. Peptide Rearrangement During Quadrupole Ion Trap Fragmentation: Added Complexity to MS/MS Spectra. Anal. Chem. 2003, 75, 1524-1535.

5. Paizs, B.; Suhai, S. Fragmentation Pathways of Protonated Peptides. Mass Spectrom. Rev. 2005, 24, 508-548.

6. Jia, C.; Qi, W.; He, Z. Cyclization Reaction of Peptide Fragment Ions During Multistage Collisionally Activated Decomposition: An Inducement to Lose Internal Amino-Acid Residues. J. Am. Soc. Mass Spectrom. 2007, 18, 663-678.

7. Polfer, N. C.; Oomens, J.; Suhai, S.; Paizs, B. Infrared Spectroscopy and Theoretical Studies on Gas-Phase Protonated Leu-Enkephalin and Its Fragments: Direct Experimental Evidence for the Mobile Proton. J. Am. Chem. Soc. 2007, 129, 5887-5897.

8. Polfer, N. C.; Bohrer, B. C.; Plasencia, M. D.; Paizs, B.; Clemmer, D. E. On the Dynamics of Fragment Isomerization in Collision-Induced Dissociation of Peptides. J. Phys. Chem. A 2008, 112, 1286-1293.

9. Mouls, L.; Aubagnac, J. L.; Martinez, J.; Enjalbal, C. Low Energy Peptide Fragmentations in an ESI-Q-Tof Type Mass Spectrometer. J. Proteome Res. 2007, 6, 1378-1391.

10. Pringle, S. D.; Giles, K.; Wildgoose, J. L.; Slade, S. E.; Thalassinos, K.; Bateman, R. H.; Bowers, M. T.; Scrivens, J. H. An Investigation of the Mobility Separation of Some Peptide and Protein Ions Using a New Hybrid Quadrupole/Travelling Wave IMS/Oa-ToF Instrument. Int. J. Mass Spec. 2007, 261, 1-12.

11. Reid, G. E.; Simpson, R. J.; O'Hair, R. A. J. Probing the Fragmentation Reactions of Protonated Glycine Oligomers via Multistage Mass Spectrometry and Gas Phase Ion Molecule Hydrogen/Deuterium Exchange. Int. J. Mass Spectrom. 1999, 191, 209-230.

12. Vachet, R. W.; Bishop, B. M.; Erickson, B. W.; Glish, G. L. Novel Peptide Dissociation: Gas-Phase Intramolecular Rearrangement of Internal Amino Acid Residues. J. Am. Chem. Soc. 1997, 119, 5481-5488.

13. Cooper, T; Talaty, E; Grove, J.; Van Stipdonk, M.; Suhai, S.; Paizs, B. Isotope Labeling and Theoretical Study of the Formation of $\mathrm{a}_{3}{ }^{*}$ Ions from Protonated Tetraglycine. J. Am. Soc. Mass Spectrom. 2006, 17 1654-1664.

14. Bythell, B. J.; Barofsky, D. F.; Pingitore, F.; Polce, M. J.; Wang, P.; Wesdemiotis, C.; Paizs, B. Backbone Cleavages of Carbon Monoxide and Sequential Loss and Ammonia from Protonated AGG: A Combined Tandem Mass Spectrometry, Isotope Labeling, and Theoretical Study. J. Am. Soc. Mass Spectrom. 2007, 18, 1291-1303.

15. Koeniger, S. L.; Merenbloom, S. I.; Valentine, S. J.; Jarrold, M. F.; Udseth, H. R.; Smith, R. D.; Clemmer, D. E. An IMS-IMS Analogue of MS-MS Anal. Chem. 2006, 78, 4161-4174. 